\title{
Study the Incidence of Fistula- in- Ano in Subsequent to Anal \\ Abscess \\ Nasir Kareem Dhahir $(\mathrm{PhD})^{1}$ \\ Abstract
}

Background: The Fistula disease is considered common surgical case in the surgical wards of the Baquba teaching hospital, and consider as a complication of the anorectal abscess. Objective: To investigate the incidence of cases that infect with fistula in ano in subsequent to different types of anorectal abscesses.

Patients and Methods: This study performed in the Baquba teaching hospital in a period from January 2016 until Jun 2018 including 216 patients (124 male and 92 female); all patients were included in the study. Samples of the patients classified into three groups according to the type of management.

Results: The results show that the high incidence of fistula in ano is appearing in patients associated with hemorrhoids $8.84 \%$, and high percent in patients who had a perianal abscess (63.48\%) Regarding the distribution of cases according to age and sex, a low percentage of cases appear in age (1-10) with $6.45 \%$ and $2.18 \%$ in males and females respectively. While the highest percentage appears in the males at age (21-30) with $37.11 \%$ and in females is at the age (11-20) with $29.35 \%$. And by the chi-square value for males is 16.37 and for females is 9.94 in a significant value of $\mathrm{p}=0.01$ and $\mathrm{p}=0.05$ respectively.

Conclusion: Fistula in ano can be associated with cases have hemorrhois, and more present with patients who have a perianal abscess, and the early drainage of the abscess can prevent development of the fistula.

Keywords: Fistula, Ano, Anorectal abscess, Internal anal sphincter

Corresponding Author: drdhahirk @ yahoo.com

Received: $7^{\text {th }}$ September 2020

Accepted: $29^{\text {th }}$ November 2020

DOI:https://doi.org/10.26505/DJM.19025560907

${ }^{1}$ Baquba Technical Institute - Middle Technical University - Diyala- Iraq

\section{Introduction}

Perianal abscesses are a common surgical emergency in all hospitals where there is in causality department and they are more common in male and high incidence being in the third and fourth decade, most anorectal fistulas are complication of anorectal abscess. Understanding the anatomy of the pelvic floor and anorectal region is very important to appreciate the origin and ramification of the fistula. Reduced to its simplest form anorectal region consist of two structures: the inner structure (the internal sphincter) and a funnel shape of pelvic floor muscles form. The first structure is the lower end of the circular muscle of the rectum which becomes thick and round while the second structure is 
formed by the levator ani, puborectalis, and external sphincter muscles [1]. The disease process has both an acute and chronic aspect. The fistula is the chronic process of the disease, persistent inflammation results in the formation of tracts from the anal duct to the ano-perineal skin. Most fistulae in ano originate in the anal crypts. An abscess is formed and when it ruptures, a fistula occurs. Hence perianal abscesses should be incised and drained promptly, but even then a fistula may result[1]. The coronal view enables positioning of the abscess and the tract with respect to the levator plate and clearly shows supralevator extension [2]. Obviously, the carcinomatous changes are due to longstanding sepsis and chronic inflammation with irritation leading to metaplasia [3].

Perianal fistula associated adenocarcinoma has also been reported in Crohn's disease [4]. Yamada K.et al [5] there is a need for special attention to be given to the similar conditions associated with malignant disease. for Andrew T. study [6] showed that fistulae result from perianal Crohn's disease, tuberculosis, or neoplasm. Most anorectal fistulas $(70 \%)$ result from a perianal abscess, tracking within the intersphincteric plane. Transphincteric fistulas result from ischiorectal abscesses and account for an additional (23\%) of cases. A supralevator abscess may result in suprasphincteric fistulas $(5 \%)$ when the tract ,originated at the dentate line. The remaining $(2 \%)$ of fistulas are extrasphincteric [7]. Anal fistulae can also develop secondary as a let complication of ileoanal pouch reconstruction surgery for inflammatory bowel disease [8]. The main objective of this study is to investigate the incidence of the fistula in ano in subsequent to different anal disease and abscesses. Idiopathic fistulas may persist if they become epithelized, a factor responsible for failure of healing of fistulas at other sites in the body [9]. And the diagnosis anorectal abscess or fistula is generally based on history and examination[10].

\section{Patients and Methods}

The study included 216 patients admitted to Baquba teaching hospital in a period from January 2016 until Jun 2018. The samples of patients consist of 124 male and 92 female including children and adults, all patients were included in the study. $60 \%$ of patients receive antibiotics irregularly before referred to the hospital. 149 patients from the total number had no previous episode of perianal abscess, 54 patients had suffered from previous one episode of anorectal abscess, 13 patients their abscess drained spontaneously and only 29 patients had associated with minor anal diseases like hemorrhoid, fissure and pruritus. 137 patients who represent all patients with the perianal type of abscess drained under local anesthesia, while the other types of abscesses drained under general anesthesia. At the first post-operative visit after at least one month, all patients underwent proctoscopy examination to find the internal opening of the fistula if it has formed.

\section{Statistical analysis}

It was done by using the percentage, Chisquare test, and significant value levels $(\mathrm{p}=0.01),(\mathrm{p}=0.05)$.

\section{Results}

Minor anal diseases were observed in 29 patients (13.4\%); hemorrhoids 19 patients 
$(8.84 \%)$, fissure 4 patients $(1.81 \%)$ and only 6 patients $(2.8 \%)$ with a strong history of pruritus, as shown in Table (1). the high incidence of the fistula in ano in the cases associated with hemorrhoids.

Table (1): Distribution of Cases in Associated Minor Anal Disease

\begin{tabular}{|l||c||c||}
\hline \hline Associated disease & Number & \% \\
\hline \hline Hemorrhoids & 19 & 8.84 \\
\hline \hline Fissure & 4 & 1.81 \\
\hline \hline Pruritus & 6 & 2.8 \\
\hline Total & 29 & 13.4 \\
\hline
\end{tabular}

In regards types of abscesses and by using the simple perianal abscess was found in 137 patients (63.48\%), ischio-rectal abscess was found in 61 patients $(28.2 \%)$ and 18 patients $(8.3 \%)$ found to have inter-sphincteric

Table (2): Distribution of Cases According to Types of the Abscesses

\begin{tabular}{|l||c||c||}
\hline Type of abscess & Number & \% \\
\hline \hline Perianal & 137 & 63.48 \\
\hline \hline Ischio-rectal & 61 & 28.2 \\
\hline \hline Inter-sphincteric & 18 & 8.3 \\
\hline \hline Total & 216 & 100 \\
\hline
\end{tabular}

In regards incidence of fistula as divided the patients into three groups, all of them have the type of anorectal abscess but some of them that developing into fistula duo to not completely healing post drainage. The first group resemble 149 patients only 46 patients $(30.8 \%)$ have fistulas, the second group 54 patients only $39(72.2 \%)$ have fistula and the third group 13 patients all of abscess as shown in Table (2). From this table the result was found that the high incidence of fistula among patients who have a perianal abscess.

Table (3): Distribution of Cases According to Incidence of Fistula

\begin{tabular}{||l||c||c||c||}
\hline Groups & Number of patients & Patients with fistula & \% \\
\hline \hline Group 1 & 149 & 46 & 30.8 \\
\hline \hline Group 2 & 54 & 39 & 72.2 \\
\hline Group 3 & 13 & 13 & 100 \\
\hline
\end{tabular}

Regards distribution of cases according to the the age and sex, the least percentage of fistula in ano was among the age (1-10) years, in males $6.45 \%$ and in females $2.18 \%$. The highest percent in males patients among the age group (21-40) years $37.11 \%, 30.65 \%$ them $(100 \%)$ have fistula as shown in Table (3)Group1:patients with no previous episode of anorectal sepsis, while the group 2: have only one previous episode of anorectal sepsis, and the group 3: have not to get proper surgical treatment of the anorectal abscess and the abscess drained spontaneously, this group is more serious than others. and in females among the age (11-30) years $29.35 \%, 28.26 \%$, and in total results in both males and females (the least result at age group 1-10 years is $4.62 \%$, and the high result at age group 21-30 years is (33.33\%) as shown in Table (4). 
Table (4): Distribution of Cases According to the Age and the Sex

\begin{tabular}{|c|c|c|c|c|c|c|}
\hline \multirow[b]{2}{*}{$\begin{array}{l}\text { Age } \\
\text { (year) }\end{array}$} & \multicolumn{2}{|l|}{ Male } & \multicolumn{2}{|c|}{ Female } & \multirow{2}{*}{ Total } & \multirow[b]{2}{*}{$\%$} \\
\hline & No. & $\%$ & No. & $\%$ & & \\
\hline $1-10$ & 8 & 6.45 & 2 & 2.18 & 10 & 4.62 \\
\hline 111-20 & 12 & 9.67 & 27 & 29.35 & 39 & 18.1 \\
\hline 21-30 & 46 & 37.11 & 26 & 28.26 & 72 & 33.33 \\
\hline 31-40 & 38 & 30.65 & 20 & 21.74 & 58 & 26.85 \\
\hline$>40$ & 20 & 16.12 & 17 & 18.47 & 37 & $\begin{array}{l}17.1 \\
\end{array}$ \\
\hline Total & 124 & $\overline{57.41}$ & 92 & 42.59 & 216 & 100 \\
\hline
\end{tabular}

\section{Discussion}

By using (Chi-square test) as shown in Table (4), the presence of correlation between the age groups and the sex, the calculated value in chi-square is 16.36 this is more than the tableted value 13.28 in a significant level of $(\mathrm{p}=0.01)$ and 9.49 in a significant level of $(\mathrm{P}=0.05)$. From this, there is a significant statistical difference between the age groups and sex. Mazier reported about anorectal fistula, there was a history of previous anorectal abscess in about $68 \%$ of the patients [11] while in my study there is a high result is $33.33 \%$ in both sexes of my patients. Scome and his colleagues have reported that $2 / 3$ of the patients who undergo incision and drainage of the abscesses will have a fistula, and other study done by themself on 232 patients with follow up for 13 years show that $34 \%$ of the patients did not develop fistula [12] . In another study did by Hughes, he state that $75 \%$ of his patients who had incision and drainage had further problems such as chronic disease, dirty, neglect and too late, but he did not specify the incidence of fistula [13]. An extensive study done in three hospitals in the United Kingdom by M.C.W Inslet, the study showed that $32 \%$ of the patients who have an anorectal abscesses and treated by the incision and drainage would develop fistula[13], this result is similar to my study results. Nalan Yildırım et al. [14] assessed the contribution of various magnetic resonance imaging (MRI) sequences in determining the type of perianal fistula and in obtaining critical information for surgical decisions, as well as to define the optimal combination of sequences for readers with varying levels of experience. Erdinc Cetinkaya et al. [15] assessed the results of the LIFT technique for the patients with complex anal fistula in Ankara NumuneTraining and Research Hospital. The results show that the successful fistula repair was achieved in the $87.5 \%$ of the patients, 3 patients had a failure at the follow-up. No incontinence was observed in any of the patients. Douglas W. [16] explained that the cryptoglandular abscess and fistula of the anal region result from obstruction of the duct of the gland, the body of which resides in the intersphincteric plane. From the result of this study, appear that $30.5 \%$ of patients with an anorectal abscess will develop a fistula, nearly the same to another study (31\%) [17]. The preferred management of these abscesses is by the incision and drainage and if the fistula subsequently, and the associated anorectal disease, all these can 
be treated at the time of fistulatomy. $80 \%$ of fistula are secondary to a cryptoglandular infection, while in other study were found $(88 \%)$ [17], and the remaindered due to Crohn's disease, trauma, radiation and malignancy [18]. The recurrence after fistulatomy is due to failure to identify a secondary fistula tract [19]. The patients who did not heal with LIFT were converted from a transsphenctric to an intersphenctric fistula then treated by fistulatomy[20]. This study found that most patients was underwnt fistulatomy only, whereas in the recent study there is the modern method to deal with fistula by Marsupialization of the tract during fistulatomy which is associated with less bleeding[20]. The presence of epithelium and the local production of antimicrobial peptides may explain the relative paucity of organisms found in chronic fistulas[21]. Another study found that the fistula is uncommon in children while this study found $(6.45 \%)$. And in the same study the fistula among the mean age of 40 years old of both sexes, while in this study the incidence among the male young 21-30 years old age (37.11\%), and females between $11-20$ years $(29.35 \%)$.

\section{Conclusions}

From the investigation results, the following conclusions are drawn:

1-The high incidence of fistula in ano in the cases associated with hemorrhoid and according to associated diseases.

2-The high incidence of fistula among patients according to types of anorectal abscesses.

3-The low incidence of fistula is detected among the children and females groups

\section{References}

[1]Forrest A. P.M.: Principle and practice of Surgery Churchill Livingston. Colorectal diseases (1983). P: 465.

[2]Halligan S, Stoker J. Imaging of fistula in ano. 2006: 239: 18-33.

[3]Yang BL,ShaoWJ, Sun GD. Perianl mucnous adenocarcinoma arising from chronic anorectal fistulae: International Journal of Colorectal disease. 2009: 24: 1001-1006.

[4]Iesalnieks I, Gaertner WB, Gia H, Struch $\mathrm{U}$, Fistula associated anal adenocarcinoma in Crohns disease. 2010: 10: 1643-1648.

[5]Yamada K, Miyakura Y, Koinuma K, Primary and secondary adenocarcinoma associated with anal fistula. 2014: 44: 888896.

[6]Andrew T. Raftery: Applied basic science. Alimentary system, Fistulae in ano, $2^{\text {nd }}$ Edition, (2008)17: 562.

[7]Whiteford $\mathrm{MH}$, Kilkenny J, Hymen N, Buie WD,: Practice parameters for the treatment of perianal abscess and fistula -in ano. Disease colon and rectum. (2005). 18:1337- 1342.

[8]Margaret Farquharson , Brendan Moran. Farquharsons textbook of operative surgery, $9^{\text {th }}$ ed. Anal Fistulae. (2005). P: 445. [9]Weiedji EP (2017)Perspectives on enterocutaneous fistula . Medical and Clinical Review 3(2): 5.

[10]Stanley M. Goldberg: Schwartz, Principle of Surgery McGraw -hill $5^{\text {th }}$ edition. Rectal disease (1988) P: 1294.

[11]Scom A. Joseph: Incidence of fistulas subsequent of anal abscesses. Colon and Rectum disease(1967), 17: 357. 
[12]Adams D.: Fistula-in-ano: Surgery Gyn. and Obstetric. (1981). 153. 731. 2.

[13]Nalan Yıldırım, Gökhan Gökalp, Ersin Öztürk, Abdullah Zorluoğlu, Tuncay Yılmazlar, İlker Ercan, Gürsel Savc1, Ideal combination of MRI sequences for perianal fistula classification and the evaluation of additional findings for readers with varying levels of experience, Diagn Interv Radiol 2012; 18:11-19.

[14]Erdinc Cetinkaya, Bekir Bulut, Siyar Ersoz, Cem Emir Guldogan, Ozgur Akgul, Bulent Cavit Yuksel and Ahmet Kessaf Aslar, Clinical Experience with Lift Technique For Complex Anal Fistulas, Cetinkaya et al., J Gastrointest Dig Syst 2016, 6:3.

[15]Douglas W. Wilmore, M.D: ACS Surgery, principles and practice, Anal procedures. $1^{\text {st }}$ Edition, (2003)19: 855.

[16]Vogel JD, Johnson EK, Morris AM, et al .Clinical practice guideline for the management of anorectal abscess, fistula -inano, and rectovaginal fistula , Dis. Colon Rectum. 2016:59: 1117-1133.

[17]A.J. Malouf, G. N, Buchanan, E. A. Carapeti, S, Rao, R, J Guy. Aprospective audit of fistula-in-ano at St. Marks hospital UK. 2001.

[18]Visscher AP, Schuar D, Sloff RAE, M eijerink WJHJ, Deen- Molenaar $\mathrm{CBH}$. Predictiv factors for recurrence of cryptoglandular fistulae characterized by preoperative three dimential endoanal ultrasound. Colorectal Dis. 2016:18:503-509. [19]Gendia AMEMA, Abd-ALRazik MA, Hanna HH. Ligation of the intersphenctric fistula tract procedure and its modifications. Coloproctal 2018:38:324-336.
[20]Kiehns K, Fincke A, Brunke G, Lange T, Folsch UR, Antimicrobial peptides in chronic anal fistula epithelium. Gastrointeral 2007:42(9): 1063-1069.

[21]Steele SR, Kumar R, Feingold DL, Rafferty JL, Standerds practice Task Force of the American Society of Colon and rectal Surgeons, Practice parameters for the managements of perianal abscess and fistulain-ano. Dis. Colon Rectum. 2011:54:14651474.

[22]Guest Editor, Gerald A. lsenberg, M.D. Anorectal Infection: Abscess-Fistula, Clin Colon Rectal Surg, 2011;24:14-21. 